\title{
Computational model to predict the temperature distribution produced by bone cement
}

\author{
Vânia C. C. Oliveira ${ }^{1}$, Elza M. M. Fonseca ${ }^{2}$, A. F. Oliveira ${ }^{3}$, Jorge \\ Belinha $^{4}$, Claúdia C. Rua ${ }^{5}$, Paulo A. G. Piloto ${ }^{6}$, Renato N. Jorge ${ }^{7}$ \\ 1,3 \\ LAETA, Centro Hospitalar do Porto, Institute of Biomedical Sciences Abel Salazar, University of Porto (CHP-ICBAS), Portugal, \\ vaniacoliveira@icbas.up.pt,afoliveira@netc.pt \\ ${ }^{2,4}$ LAETA, INEGI, School of Engineering, Polytechnic of Porto (ISEP), Mechanical Engineering Department, Portugal, \\ elz@isep.ipp.pt,job@isep.ipp.pt \\ 5, 6 LAETA, INEGI, Polytechnic of Institute of Bragança (IPB), Department of Applied Mechanics, Portugal, \\ claudiarua_17@hotmail.com,ppiloto@ipb.pt \\ ${ }^{7}$ LAETA, INEGI, Faculty of Engineering of the University of Porto (FEUP), Mechanical Engineering Department, Portugal,
} rnatal@fe.up.pt

\begin{abstract}
Bone is the third frequent location for haematogenous dissemination of malignant tumors. Patients with multiple bone metastases are exponentially growing. Bone metastases, which are frequently diagnosed late, are associated to imminent and pathological bone fractures. Metastatic disease translates an advanced tumor stage and it has a high impact in patients' quality of life and survival. The main objective is to study the thermal effect induced by the bone cement polymerization, in the bone metastatic tumor reduction and to understand the role of such procedure and its biomechanical stabilization. To assess the clinical effect, it is important to test this methodology before its application and obtain sustained results. In this work, a computational model was developed to predict the temperature distribution produced by cement polymerization, and verify the reduction of the metastatic tumor area due the thermal effect. Different simulations produced to evaluate the necrosis effect for two cement amount sizes introduced in a cortical and spongy bone tumor. The same computational models were reproduced introducing an endomedular nail in titanium and a femoral stem in cobalt-chrome material in pathological bone fractures. DOI: https://doi.org/10.24243/JMEB/3.2.195_X

$\underline{\text { Research Article }}$

$\begin{array}{cl}\text { Article History } \\ \text { Received } & 19 / 02 / 2018 \\ \text { Revised } & 15 / 03 / 2018 \\ \text { Accepted } & 18 / 05 / 2018\end{array}$

Recommended by Editorin-Chief André Ferreira Costa Vieira

\section{Introduction}

Bone tumors could be benign or malignant, and primary or metastatic due to systemic cancer cells dissemination. They destroy bone and may lead to pathologic fractures. It is important for the multidisciplinary team and specially for the orthopaedic surgeon to characterize the bone tumor lesion with specific attention to identify the size, type (osteolytic, osteoblastic, mix), location, periosteal reaction, cortical involvement, etc. in the involved bone [1]. Bone cement (PMMA or polymethylmethacrylate) is widely used in orthopaedic surgeries due to their properties,. 
excellent biocompatibility and easy manipulation. This material has an exothermic reaction where volumetric dimension changes during the polymerization process with heat generation [2]. The high heat generated can lead to thermal necrosis of bone cells and also residual stresses formation that can affect the endomedular systems fixation and loosening. Different authors studied the exothermic reaction of cement polymerization and reported in different publications results regarding the temperature rise using time-dependent polymerization process [2 - 3]. There are studies in the literature documenting experimental measured temperatures that indicate thermal necrosis in cortical bone, usually when it reaches a temperature of $47^{\circ} \mathrm{C}$ for $1 \mathrm{~min}[4-5]$. Other authors showed that temperature values above $55^{\circ} \mathrm{C}$ for a period longer than 30 seconds could cause great irreversible lesions in bone tissue [4, 6 - 7]. Eriksoon and Albrektsson [8] concluded that heating up to $47^{\circ} \mathrm{C}$ could be considered as the optimal limit that bone can withstand without necrosis. In another investigation, the thick cement showed maximum temperature approximately $45^{\circ} \mathrm{C}$ [9]. The temperature generation during the bone cement cure depends on the balance between the heat generation and the heat transfer rate. The higher the initial temperature, the higher rate of heat transfers from cement to the bone [9]. Others authors focused on empirical models for the prediction of heat generated using experimental and computational results [10 - 14]. In this paper a two dimensional thermal and transient model based on finite element method was built to predict the temperature field produced by cement polymerization in metastatic bone tumor lesion. The bone cement PMMA was introduced to fill in a metastatic lytic lesion area with or without endomedular nail, and femoral stem, in two different materials. The main objective is to investigate the role of such procedure in bone tumor necrosis due to thermal effects and its biomechanical stabilization. Two different geometries were tested to represent tumor lesion models with or without an internal endomedular nail in titanium and a femoral stem in cobalt-chrome, as a biocompatible material. In total six computational models were developed. For each model, the temperature field due to the cement polymerizing effect is represented, which affects thermal necrosis and the amount of bone cells penetration. For a more efficient clinical benefit, all results were presented to stimulate a discussion regarding if the introduction of PMMA is an alternative procedure in a metastatic lytic lesion reduction with the influence of the different endomedular material.

\section{Materials and Methods}

\subsection{Clinical X-ray measurements}

Computational models were built according to average dimensions of the sub-trochanteric femoral area, obtained from digital X-ray from patients of CHP-ICBAS and proved from a biomechanical data control group [15]. In the middle of the model, bone cement was introduced to fill in a metastatic lytic lesion area minimization with the dimensions equal to $20 \mathrm{~mm}$ in depth and variable width of 15 and $25 \mathrm{~mm}$. Two computational models were reproduced without a femoral intramedullary system and with two extra models with the endomedular nail and femoral stem, with a diameter equal to $11 \mathrm{~mm}$. The bone lytic lesions were filled with PMMA. When the intramedullary systems are included, the cement material was spread in the same quantities through the spongy bone. Figure 1 a) shows two metastatic lytic lesions of the proximal left femur (sub-trochanter) identified on a plain pelvic X-ray, where the patient was diagnosed with metastatic disease of a breast cancer. The right image represents other metastatic lytic lesion on the diaphysis femur of a male patient with clear renal cells carcinoma. Both metastatic lytic lesions have in width between 16 and $25 \mathrm{~mm}$ and $20 \mathrm{~mm}$ in depth. The size characterization of the metastatic lesions is important to introduce the same dimensions for bone cement amount. Figure $1 \mathrm{~b}$ ) shows the measurement of the proximal femur (sub-trochanteric area) based on conventional pelvic X-ray of 2 patients of CHP-ICBAS with determination of the internal and external cortical bone, spongy bone and complete femoral diaphysis diameter. In average, the measured bone geometries considered for the computational model have an external diameter equal to $31.2 \mathrm{~mm}$ and a cortical thickness of $7.35 \mathrm{~mm}$.

Figure 2 shows a conventional A-P and lateral X-ray of two patients submitted to internal fixation using a femoral intramedullary nail (Gamma nail 3, Stryker®). Both patients presented an imminent or pathological fracture due to bone metastases of different primary tumors.

Figure 3 consists on A-P view X-rays of a pathological fracture of the right femoral neck and after the hip arthroplasty as its palliative treatment. The patient presented a metastatic disease. 


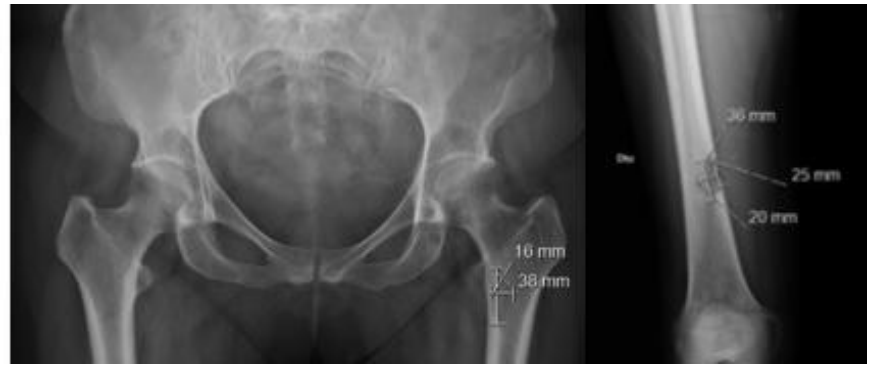

a)

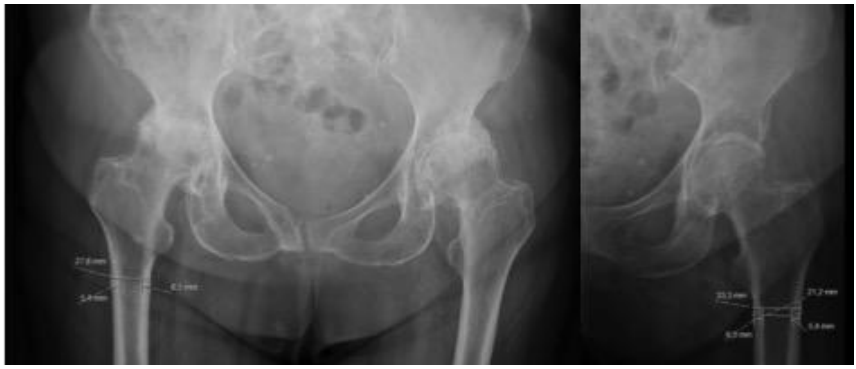

b)

Fig. 1 a) Metastatic lytic lesion of the proximal left femur and on the diaphysis of the right femur; b) Measurements.

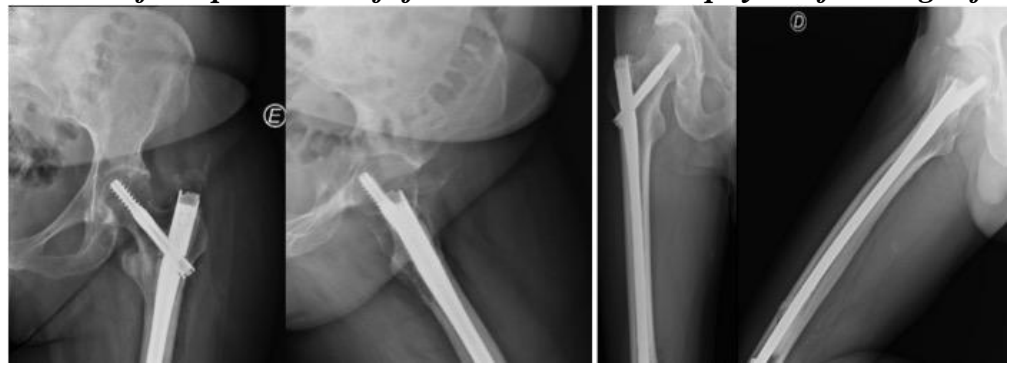

Fig. 2 Internal fixation with a femoral intramedullary nail.

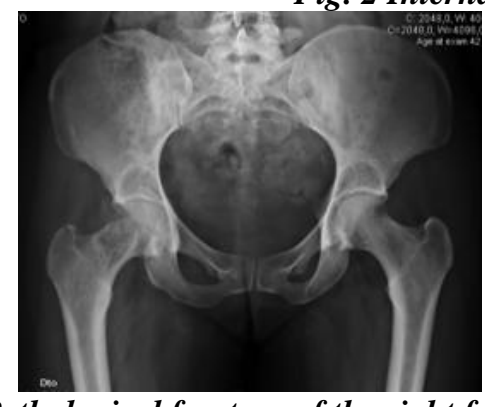

Fig. 3 a) Pathological fracture of the right femoral neck

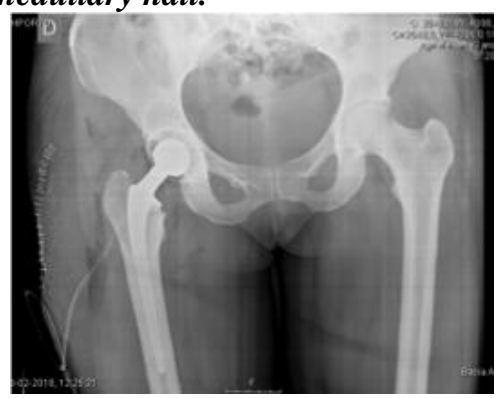

b) Cemented total hip replacement presenting the femoral stem.

\subsection{Computational models}

In this study, a two-dimensional computational model was used to simulate the temperature field inside the bone material during the cement polymerization process. The simulations were performed using the finite element method with ANSYS Multiphysics software. The geometrical model was meshed with a 2D thermal solid element (PLANE 77) with 8 nodes and a single degree of freedom, temperature, at each node. Table 1 represents all thermal material properties for cortical bone, spongy bone, cement, titanium and cobalt-chrome, assumed constant and isotropic, achieved from the literature [2, 16 - 17]. The thermal diffusivity is related with the conductivity divided by material density and specific heat capacity. It measures the rate of heat transfer of a material from the hot to the cold side. The material with high thermal diffusivity, allows the heat to flows rapidly and quickly conducts heat [17]. The interaction region between all materials was considered as perfect contact. The heat transfer between different materials is performed exclusively by heat conduction. The boundary conditions considered in these analyses are the prescribed temperature in the bone cement region. The entire model is assumed to have the same initial temperature of $37^{\circ} \mathrm{C}$. The temperature transient effect in PMMA was introduced in the computational model in accordance with experimental results from literature [11], represented in figure 4. During the PMMA exothermic phase, there is no significant endomedular blood flow increase. According to the duration of cement polymerization, a total simulation time equal to $1800 \mathrm{~s}$ was established: $384 \mathrm{~s}$ of heating followed by $1416 \mathrm{~s}$ of cooling. The time at the end of the simulation was 1800 s with an incremental time step equal to $5 \mathrm{~s}$.

Table 1 Thermal material properties.

\begin{tabular}{lcccc}
\hline Material & Density, $\mathrm{kg} / \mathrm{m}^{3}$ & Conductivity, W/K.m & Specific heat, $\mathrm{J} / \mathrm{kgK}$ & Thermal diffusivity, $\mathrm{m}^{2} \mathrm{~s}^{-1}$ \\
\hline Cortical Bone & 2100 & 0.38 & 1260 & $1.44 \mathrm{E}-07$
\end{tabular}




\begin{tabular}{lcccc} 
Spongy Bone & 620 & 0.39 & 4926 & $1.28 \mathrm{E}-07$ \\
Cement PMMA & 1100 & 0.20 & 2000 & $9.09 \mathrm{E}-08$ \\
Titanium & 8900 & 29.00 & 377 & $8.64 \mathrm{E}-06$ \\
Cobalt-chrome & 8768 & 14.80 & 452 & $3.73 \mathrm{E}-06$ \\
\hline
\end{tabular}

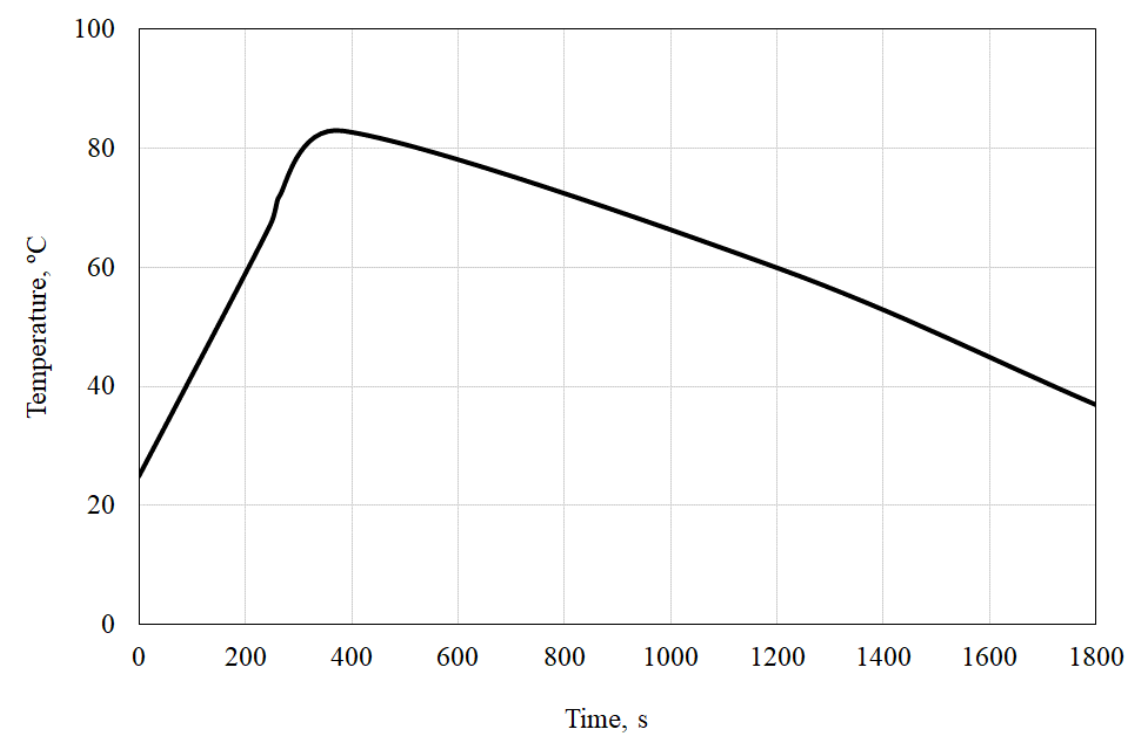

Fig. 4 Time-temperature curving effect in PMMA

\section{Results and Discussion}

Figure 5 represents two computational models without any femoral intramedullary nail system or femoral stem. This figure also presents the temperature field calculation for time equal to 384s. The cyan zone represents the cortical tissue, violet region represents the spongy bone and red colour represents the PMMA cement effect using two different widths to fill a metastatic lytic lesion area. For each model, the temperature field, obtained due to the cement polymerizing effect, is represented in the time instant equal to the maximum polymerization cement temperature peak, time equal to 384s. The results show that the temperature in PMMA zone reaches the maximum value of $83^{\circ} \mathrm{C}$ and that the heat is spread through cortical and spongy bone. The thermal necrosis effect in bone tissue without the endomedular nail is represented in grey colour. Increasing the amount of the metastatic lytic lesion filled with PMMA cement (from 15 to $25 \mathrm{~mm}$ in width), the thermal necrosis increases the surrounding spongy region width of $10 \mathrm{~mm}$ equal in both models, increasing in lateral corners of the cement zone with more pronounced effect in depth. Figure 6 represents the same computational models but including the titanium intramedullary nail and the femoral cobaltchrome stem, represented both by the dark blue colour. The intramedullary fixation pressures the bone cement to fill from one cortical bone to another, around the nail or stem. The temperature distribution is represented by time of the peak temperature for cement polymerization. In the lytic lesion (and with the consequent increase of PMMA filling), the heat affects all bone tissue diameter due the good conductivity properties of the titanium and cobalt-chrome endomedular systems. All cement filling induced in the metastatic lytic lesion area affects the spongy bone and the cortical bone, and even small cement quantities produce high temperature in the surrounding region. When comparing the temperature field between the two materials used for the endomedular systems, the titanium presents the highest affected area. This effect is justified by its high thermal diffusivity and conductivity.

Width cement equal of $15 \mathrm{~mm}$

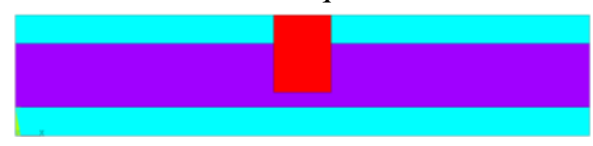

Width cement equal of $25 \mathrm{~mm}$

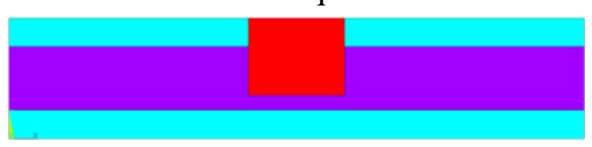




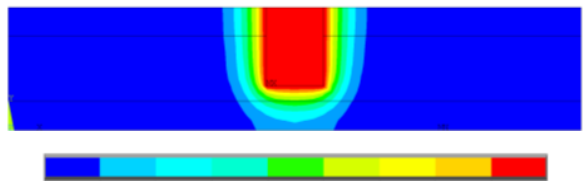

$37^{\circ} \mathrm{C}$

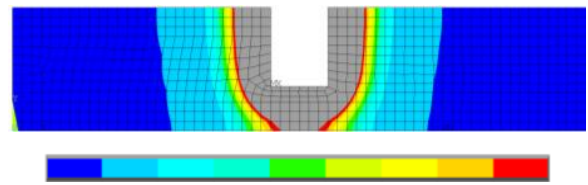

$37^{\circ} \mathrm{C}$

$45^{\circ} \mathrm{C}$

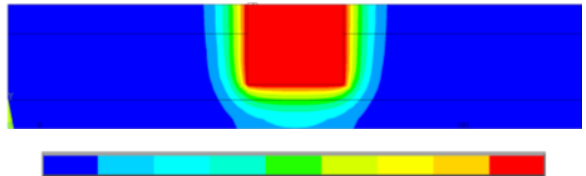

$83^{\circ} \mathrm{C}$

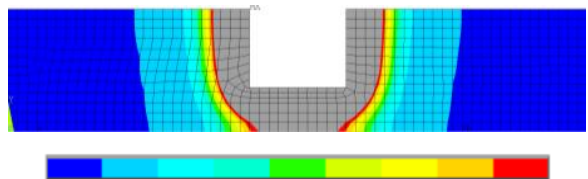

$37^{\circ} \mathrm{C}$

Fig. 5 Geometries without endomedular nail, temperature at high peak polymerization, time=384s.

Width cement equal of $15 \mathrm{~mm}$

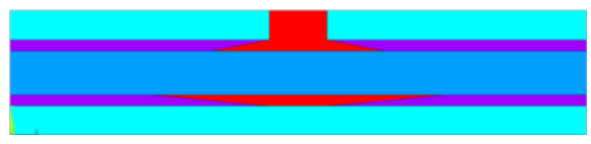

Titanium endomedular nail

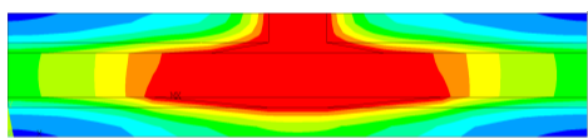

Cobalt-chrome femoral stem

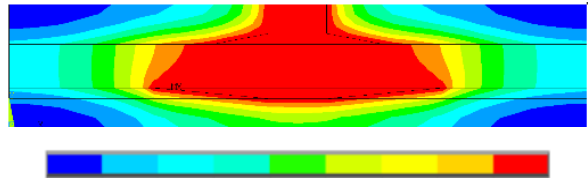

$37^{\circ} \mathrm{C}$

$83{ }^{\circ} \mathrm{C}$
Width cement equal of $25 \mathrm{~mm}$

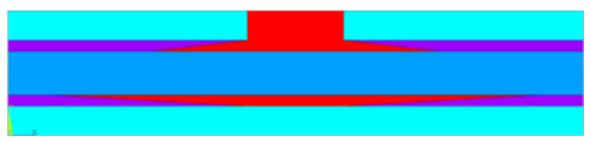

Titanium endomedular nail

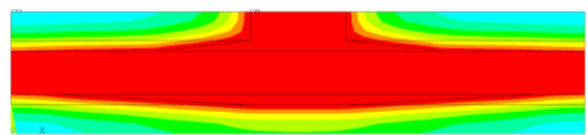

Cobalt-chrome femoral stem

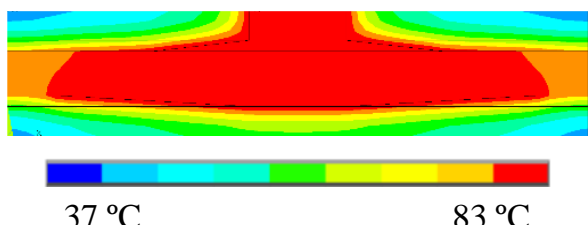

$37^{\circ} \mathrm{C}$ $83^{\circ} \mathrm{C}$

Fig. 6 Geometries for endomedular systems in titanium or cobalt-chrome, temperature at high peak polymerization, time=384s.

\section{Conclusions}

The computational results allow to conclude about the high temperature spread effect in bone material. The temperature field located on the endomedular systems induces heat transfer in all the models due to higher conduction effect from the metallic material (titanium or cobalt-chrome) used in endomedular nail and femoral stem, justified by the high material conductivity and thermal diffusivity. From the results, it can be concluded that with an increase in the lytic lesion and cement width, the thermal necrosis produces the same bone effect by adding the affected dimension by the amount of cement. There was a significant temperature difference between the different cement amounts used in this study due to the inclusion of the two endomedular systems, where the maximum temperatures at the bone increases significantly. Furthermore, the titanium endomedular nail has shown to be a better heat conductor, when compared to the cobalt-chrome femoral stem. As a conclusion, bone cement filling and the structural stabilization with an endomedular nail or femoral stem appears to have a synergic effect that can be applied to long bones metastatic lytic lesions treatment on a clinical practical application.

\section{References}

[1] The Esmo/European Sarcoma Network Working Group. Bone sarcomas: ESMO Clinical Practice Guidelines for diagnosis, treatment and follow-up. Annals of Oncology. 2014: 25(Supplement 3): iii113-iii123

[2] Pérez MA, Nuño N, Madrala A, García-Aznar JM, Doblaré M. Computational modelling of bone cement polymerization: temperature and residual stresses. Computers in biology and medicine. 2009 Sep 1;39(9):751-9. DOI: https://doi.org/10.1016/j.compbiomed.2009.06.002 
[3] Huiskes R. Some fundamental aspects of human joint replacement: analyses of stresses and heat conduction in boneprosthesis structures. Acta Orthopaedica Scandinavica. 1980 Oct 1;51(sup185):3-208. DOI: https://doi.org/10.3109/ort.1980.51.suppl-185.01

[4] Tu YK, Chen LW, Ciou JS, Hsiao CK, Chen YC. Finite Element Simulations of Bone Temperature Rise During Bone Drilling Based on a Bone Analog. J Med Biol Eng. 2013: 33:269-274.

[5] Eriksson AR, Albrektsson T. Temperature threshold levels for heat-induced bone tissue injury: a vital-microscopic study in the rabbit. Journal of prosthetic dentistry. 1983 Jul 1;50(1):101-7. DOI: https://doi.org/10.1016/0022-3913(83)90174-9

[6] Hillery MT, Shuaib I. Temperature effects in the drilling of human and bovine bone. Journal of Materials Processing Technology. 1999 Aug 30;92:302-8. DOI: https://doi.org/10.1016/S0924-0136(99)00155-7

[7] Maria G Fernandes, Elza M Fonseca, Renato N Jorge, Maria C Manzanares, Maria I Dias. Effect of drill speed on the strain distribution during drilling of bovine and human bones. Journal of Mechanical Engineering and Biomechanics. 2018: 2(5):69-74.DOI: https://doi.org/10.24243/JMEB/2.5.170

[8] Eriksson RA, Albrektsson T. The effect of heat on bone regeneration: an experimental study in the rabbit using the bone growth chamber. Journal of Oral and Maxillofacial surgery. 1984 Nov 1;42(11):705-11. DOI: https://doi.org/10.1016/0278-2391(84)90417-8

[9] Gundapaneni D, Goswami T. Thermal isotherms in PMMA and cell necrosis during total hip arthroplasty. Journal of applied biomaterials \& functional materials. 2014 Sep;12(3):193-202. DOI: 10.5301/jabfm.5000196

[10] Baliga BR, Rose PL, Ahmed AM. Thermal modeling of polymerizing polymethylmethacrylate, considering temperaturedependent heat generation. Journal of Biomechanical Engineering. 1992 May 1;114(2):251-9.DOI: https://doi.org/ 10.1115/1.2891379.

[11] Santos Jr JG, Peixoto LS, Nele M, Melo PA, Pinto JC. Theoretical and Experimental Investigation of the Production of PMMA-Based Bone Cement. InMacromolecular Symposia 2006 Nov (Vol. 243, No. 1, pp. 1-12). Weinheim: WILEY-VCH Verlag.

[12] Maria G Fernandes, Elza MM Fonseca, Tiago AS Teixeira, Renato N Jorge. Dynamic numerical simulation of different drill bit diameter on the polyurethane foams drilling. International Journal of Science and Technology. 2017: 3(3):01-12. DOI-https://dx.doi.org/10.20319/mijst.2017.32.112

[13] Maria G Fernandes, Elza M Fonseca, Renato N. Natal. Assessment of different drill diameter on bone drilling process. Journal of Mechanical Engineering and Biomechanics. 2017: 1(6):135-141. DOI:https:/doi.org/10/24243/JMEB/6.1.151

[14] MG Fernandes, EMM Fonseca, RN Jorge, M Vaz, MI Dias. Thermal analysis in drilling of ex vivo bovine bones. Journal of Mechanics in Medicine and Biology. 2017: 17(5): (16pages). DOI:10.1142/S0219519417500828

[15] Jae, HY, Tae GJ, Arjun RH, Jae MC, Chang HH, Tae YK, Seung WS. The Analysis of Biomecahnical Properties of proximal after Implant Removal. Applied Bionics and Biomechanics, Hindawi Publishing Corporation. 2016: 10 pages

[16] Ikekwem, JU, Chukwuneke JJ, Omenyi SN. Thermal Behavior of Bone cement in Hip Replacement. Physical Science International Journal. 2018: 17(4):1-14

[17] Szymon Baron, Eamonn Ahearne, Pat Connolly, Shane Keaveney, Gerry Byrne. An Assessment of Medical Grade Cobalt Chromium Alloy ASTM F1537 as a "Difficult-to-Cut (DTC)" Material. The Proceedings of MTTRF 2015. 